\title{
Medical criteria to indicate and remove alternative feeding routes in hospitalized older adults
}

\author{
Mariana Rebeka Gomes Queiroz' \\ https://orcid.org/0000-0003-2109-1960 \\ Catharina Ximenes de Moura ${ }^{1}$ \\ https://orcid.org/0000-0002-2420-4580 \\ Julia da Silva Marinho² \\ https://orcid.org/0000-0003-3077-3197 \\ Luiza Maggioni ${ }^{1}$ \\ https://orcid.org/0000-0001-7332-8005
}

Instituto de Medicina Integral Professor Fernando Figueira, Recife, Pernambuco, Brasil.

2 Hospital Agamenon Magalhães, Recife, Pernambuco, Brasil.

Conflict of interests: Nonexistent

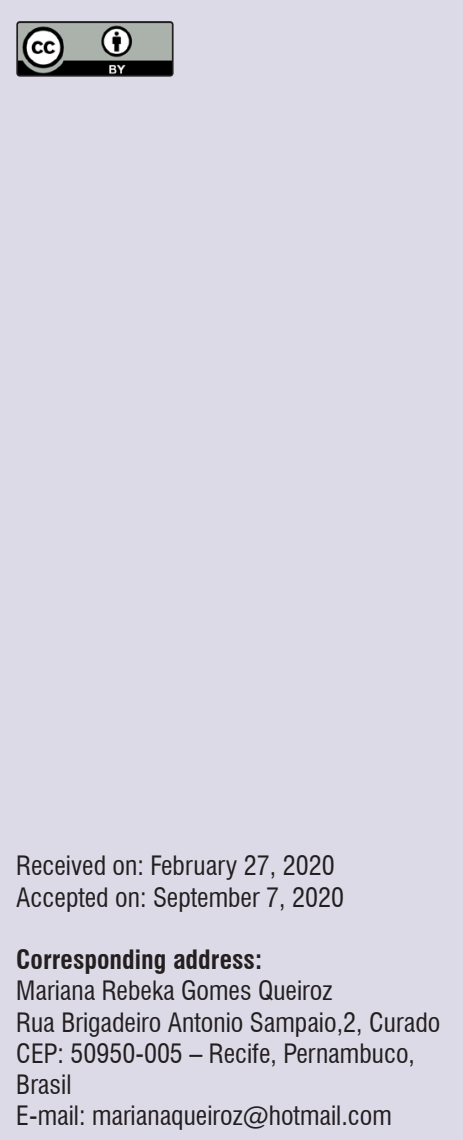

\section{ABSTRACT}

Purpose: to describe the medical criteria and the role of the speech therapist's procedure in indicating and removing alternative feeding routes in older adults.

Methods: a cross-sectional study conducted with the medical team of a public hospital. A questionnaire was administered with items on the medical criteria to indicate and remove alternative feeding routes and on the speech therapist's work. Descriptive statistics were used for categorical variables in relative and absolute frequencies.

Results: the data obtained from the participation of the 59 physicians enabled the main criteria for the indication of an alternative feeding route to be defined as follows: consciousness level, clinical condition, nutritional status, respiratory condition, and dysphagia assessment by a speech therapist. The main criteria for the removal of the alternative feeding route were the stable clinical and respiratory conditions, adequate nutritional support, and recommendation by a speech therapist.

Conclusion: the clinical and respiratory conditions, nutritional status, and the speech therapist's procedure were the main criteria considered by the medical team in the decisions to indicate and remove the alternative feeding route. The work of the speech therapist was relevant in both medical decisions, regarding the alternative feeding route in older patients.

Keywords: Aged; Enteral Nutrition; Speech, Language and Hearing Sciences 


\section{INTRODUCTION}

The increase in the older adult population made it necessary to turn an analytical eye on the aspects of aging $^{1}$, particularly the feeding issues. During a hospital stay, the older adult can have difficulties ingesting food $^{2-4}$. Hence, the conditions found in the literature ${ }^{5-7}$ for the indication of alternative feeding routes (AFR) in older adults are decreased consciousness level, neurologic and/or respiratory changes, food refusal, and dementia. Given the need for adequate nutritional support, the medical and multiprofessional team analyzes and discusses the indication for the removal of AFR, following previously established criteria ${ }^{6-7}$.

Documents, issued as a resolution ${ }^{8}$ and an evaluation report ${ }^{9}$, state that the speech therapists are apt to integrate the team as a member that will aid in the medical decision of indicating and removing the AFR when the risk of laryngotracheal aspiration is identified.

On the other hand, even though the speech therapist is secured participation in the process of establishing these criteria, there is a shortage of studies analyzing the professional relationship between physicians and speech therapists when dealing with the AFR indication and removal criteria, especially in older patients.

In this context, this research stands out for its approach to the main criteria established by the physicians regarding the indication and removal of this feeding route. It also allows for the analysis of the influence of the speech therapist's participation in the medical conduct in these cases, especially in the older population. Hence, this paper aimed to describe the medical criteria and the role of the speech therapist in the indication for and removal of AFR in older adults.

\section{METHODS}

This study was approved by the research ethics committee of the Hospital Instituto de Medicina Integral Professor Fernando Figueira, in Recife, Pernambuco, Brazil, under number 90792828.5.0000.5201. This cross-sectional research was carried out in the ICUs (Intensive Care Units) and wards of the said institution, which works in the fields of teaching, research, outreach, and community assistance focused on the child, women's, and men's health.

A total of 59 physicians that cared for older patients in the wards and ICUs were invited to participate in this study. These professionals had different specialties, from intensivists to clinicians. The sample was selected by convenience, according to the professionals' availability in the recovery room, in order not to hinder their work. They agreed with and signed the informed consent form (ICF).

The data were collected with a questionnaire to investigate the aspects related to the indication for and removal of AFR in older adults (Appendix 1), developed by the authors based on the literature ${ }^{6,7,10}$ and clinical practice. The said instrument has multiplechoice questions approaching the following aspects: list of medical criteria to indicate AFR; the frequency with which the physicians request the assessment of a speech therapist to indicate AFR; list of medical criteria to request the assessment of a speech therapist when the patient is already using an AFR; medical conduct when the speech therapist follows up on a patient with an AFR; list of medical criteria to remove the AFR; and medical analysis of the degree of importance of the speech therapist's work in the process of removing the AFR.

Initially, a pilot study was conducted with five physicians not included in the research, to validate and adjust the items in the questionnaire. After this phase, the new instrument was handed to be filled out by the physician, yet with no explanations from the assessor.

The inclusion criterion was ICUs and wards that treated older patients. The exclusion criteria were unanswered or incompletely answered questions.

This research considered the medical population, classified as interns and preceptors. The former are the physicians in specific residency programs, who are assisted by the preceptors in their clinical training. The second group involves professional physicians, who have more clinical experience and are responsible for guiding the residents.

Another point considered was the comfort diet, offered as a feeding option that provides safety and momentary pleasure to the patients, thus avoiding the risk of bronchoaspiration.

The data were used in STATA/SE 12.0 and Excel 2010. The tests were applied with 95\% confidence. The results of the categorical variables were presented in tables, with their respective absolute and relative frequencies.

Fisher's exact test was used to verify possible associations between the categorical variables. All the analyses were carried out in SPSS (Statistical Package for the Social Sciences) for Windows, version 13.0. 


\section{RESULTS}

The characterization of the medical team revealed a greater representation of men, 30 to 49 years old, medical residents, with a professional experience of up to five years, attending older patients in the medical clinic (Table 1).

Table 1. Distribution of the sociodemographic variables of the medical team

\begin{tabular}{lccc}
\hline Variables & & N & $\%$ \\
\hline \multirow{2}{*}{ Sex } & Males & 27 & 45.8 \\
& Females & 32 & 54.2 \\
\hline \multirow{2}{*}{ Age } & $18-29$ years & 28 & 47.5 \\
& $30-49$ years & 29 & 49.2 \\
\hline \multirow{2}{*}{ Position } & $50-60$ years & 2 & 3.4 \\
\hline \multirow{3}{*}{ Professional training } & Medical preceptor & 22 & 37.3 \\
& Medical resident & 37 & 62.7 \\
\hline \multirow{3}{*}{ Time of experience } & Specialization & 6 & 10.2 \\
& Medical residency & 49 & 83.1 \\
& Master's degree & 3 & 5.1 \\
\multirow{2}{*}{ Department } & Doctor's degree & 1 & 1.7 \\
\hline
\end{tabular}

Legend: ICUs = Intensive Care Units

The following criteria stood out among those used to indicate AFR in older patients: consciousness level, assessment of dysphagia by a speech therapist, clinical condition, nutritional status, underlying disease, and respiratory condition (Figure 1).

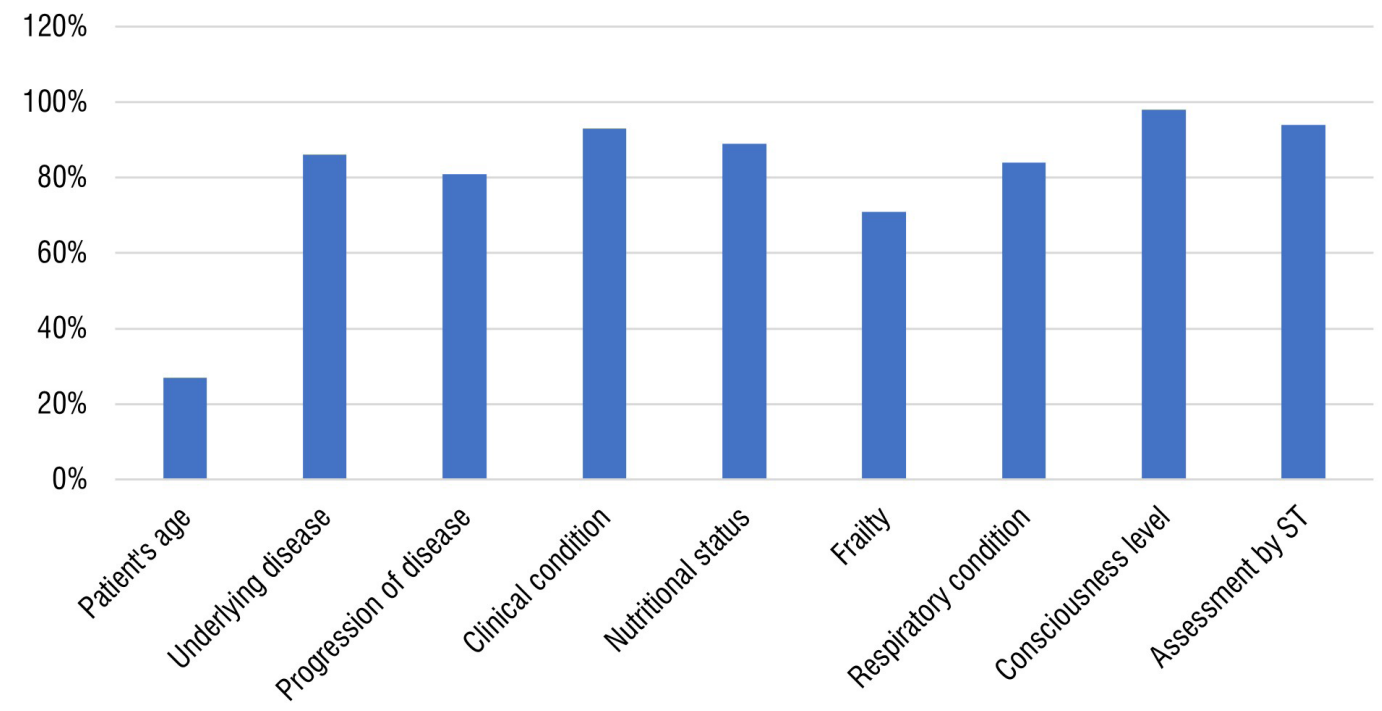

Legend: ST $=$ speech- therapist

Figure 1. Medical criteria to indicate an alternative feeding route in older adults 
Regarding the frequency with which an assessment by a speech therapist is requested to indicate an AFR, a high recommendation was observed: always/frequently (71.2\%), and occasionally/rarely/never (28.8\%).

In the case of patients using an AFR, the main medical criteria to ask for a speech therapist were the extubation assessment, complaints of dysphagia, and risk of bronchoaspiration. On the other hand, inappetence was not considered.
As for the medical conduct when a speech therapist treats a patient with AFR, it was noticed that the cases are recurrently discussed. Also, reading the medical records were highlighted as constant (59.3\%) and occasional (40.7\%).

The prevailing medical criteria for the removal were the recommendation by a speech therapist, stable respiratory pattern, adequate nutritional support, and stable clinical pattern (Table 2).

Table 2. Medical criteria to remove the alternative feeding route in older adults

\begin{tabular}{lccc}
\hline Criteria & & $\mathbf{N}$ & $\%$ \\
\multirow{2}{*}{ Stable clinical condition } & Yes & 53 & 89.8 \\
& No & 6 & 10.2 \\
\hline \multirow{2}{*}{ Stable respiratory pattern } & Yes & 57 & 96.6 \\
\multirow{2}{*}{ Adequate nutritional support } & No & 2 & 3.4 \\
\hline \multirow{2}{*}{ Recommendation from a speech therapist } & Yes & 54 & 91.5 \\
\multirow{2}{*}{ Hospital discharge } & No & 5 & 8.5 \\
\hline \multirow{2}{*}{ Comfort diet } & Yes & 57 & 96.6 \\
& No & 2 & 3.4 \\
\hline
\end{tabular}

Concerning the medical analysis of the importance of the speech therapist to the removal of the AFR, a high degree of prominence was given to this professional's work at this moment. It was considered extremely important by $71.2 \%$, very important by $23.7 \%$, and moderately important by $5.1 \%$.

\section{DISCUSSION}

The indication for or removal of the AFR is one of the recurrent themes in medical and multiprofessional team discussions. Hence, the speech therapist must participate in these occasions of clinical discussion to call attention to factors related to dysphagia - which either favors or hinders the indication for or removal of an AFR. The physician needs the assessment of the speech therapist to safely guide the decision on which is the adequate feeding route to the patient.

In this paper, the profile comprised male resident physicians, aged 30 to 49 years, with up to five years' experience, attending older patients in the various areas of health care. Such a reality portrays that the recently graduated physicians are assisting the older population in various settings of hospital stay.

Concerning the medical criteria to indicate AFR, the studies point to justifications similar to those found in this paper: decreased consciousness level, an association between decreased consciousness level and respiratory impairment, the presence of dysphagia, and serious overall condition ${ }^{7,11}$. Hence, dysphagia is noticeably a predominant factor, making it necessary to count on the work of a speech therapist in the team to deal with these cases.

The presence of these criteria indicates that a worsened clinical condition leads to a decreased consciousness level. It also brings about changes in the nutritional status and impairment of the respiratory condition. These circumstances lead to the risk of dysphagia. Thus, the assessment by a speech therapist must consider these risk factors, as well as the true need for AFR to ensure nutrition and improve the clinical aspects ${ }^{12,13}$.

Age was not considered a relevant criterion to introduce an AFR, which can be explained by the 
importance given to the complexity of the clinical condition and not only the age as an isolated factor. Nevertheless, it is known that older adults have presbyphagia - i.e., the aged swallowing represented by reduced muscle activity. Hence, they present symptoms such as coughing and/or choking, multiple swallowing, and the suggestive signs of glottal incompetence ${ }^{14}$.

In the present research, requesting a speech therapist as a medical criterion had a relevant degree for the indication of AFR. It is worth highlighting that the continuous presence of medical residents in the multiprofessional team helps identify symptoms of dysphagia. Thus, the speech therapist is required, consequently leading to the observation of this professional works as the case evolves.

The assessment by a speech therapist is essential to analyze the swallowing biomechanics, in order to establish a clinical diagnosis of this function. In case there is a disorder, instructions are given to avoid the risk of dysphagia and/or oropharyngeal dysphagia rehabilitation ${ }^{12}$. Associated with this facet, if the patient's feeding condition requires the indication for or removal of an AFR, the physician must ask the speech therapist to carry out the assessment procedure for future medical decision-making.

Regarding the request for a speech therapist when the patient is already using an AFR, this professional's intervention is important to assess the swallowing biomechanics aiming at the progress of the diet and the safe extubation, returning to oral feeding. This is particularly the case with tracheotomized patients in mechanical ventilation in an intensive care unit ${ }^{15,16}$.

The medical criteria to require a speech therapist to assess a patient that is using an AFR were the extubation of the alternative route, complaints of dysphagia, and risk of bronchoaspiration. The requirement in this context is justified by the need for a specific assessment to investigate the swallowing biomechanical process when there are complaints of dysphagia ${ }^{17}$ and the risk of bronchoaspiration ${ }^{18}$ - especially the assessment of the possibility of progressing the diet with future removal ${ }^{19}$ of this AFR.

Inappetence was considered a nonrelevant factor for the request, probably for being related to the following aspects: disliking the taste/preparation of the hospital food, lack of appetite, depression, pain, nausea, and vomit ${ }^{20}$. Such a fact can be commonly found in patients using an AFR, which is underreported, and little described in the medical record ${ }^{7}$.
The medical conduct when the speech therapist is following up a patient revealed that the physicians value this therapist's work in the recurrent readings of the speech therapist's records and discussions with the professional to deal with the case in depth.

In the present research, one of the points that impact the medical decision to remove the AFR is the assessment by the speech therapist, along with other medical criteria, such as the stable clinical and respiratory condition and the reach of the nutritional support. Regarding the impact of this decision, the speech therapist has the essential role of presenting the assessment results as basic information for the case to be understood and also to be the basis to develop the treatment and future interventions, especially when feeding and extubation issues are involved ${ }^{14}$. Thus, the procedure is made safe in terms of swallowing, with less risk of reintroducing the AFR.

The criteria of indication for and removal of the AFR did not present significant differences. Nonetheless, they stood out in both moments and had higher percentages when related to a clinical condition, respiratory condition, nutritional status, and speech therapist's conduct.

However, the discharge was not considered an influencing aspect for the removal, probably because the medical decision determines the hospital leave regardless of removing the AFR.

The comfort diet had similar responses, with a lower score in the removal - which can be associated with the unfamiliarity with the term, especially regarding the experience in palliative care. Even so, the literature points out that the use of feeding tubes in patients with advanced dementia is contraindicated. Instead, it suggests that they be given safe oral feeding, considering the patient's desire and, most of all, the swallowing with no signs of suffering and risks of bronchoaspiration $^{21,22}$.

The medical analysis of the speech therapist's work in the removal process showed that these professionals understand the importance of such therapists for this decision. However, the relationship between the medical criteria for the removal and the speech therapist's work was not significant. This was possibly due to the relevance given by the medical conduct to the other factors that can influence the hospital discharge (clinical condition, respiratory condition, nutritional support, and need for a comfort diet).

This research was conducted in different hospital departments, which proved to be one of its 
limitations. Another limitation was the administration of the questionnaire by a speech therapist, which may have led to biased responses.

For future research, it is suggested that the investigation be conducted in another hospital setting since this is a teaching, research, and outreach institution, in which the physicians work along with the multiprofessional team.

\section{CONCLUSION}

The main medical criteria found to indicate and remove the feeding route were the clinical condition, respiratory condition, nutritional status, and the conduct of the speech therapist. This therapist's work was relevant in both medical decisions regarding the alternative feeding route in older patients. Based on the physician's standpoint regarding the need for the participation of the speech therapist when indicating and removing the AFR, it is concluded that physicians consider it appropriate to have the technical, scientific, and clinical support of the speech professional, to establish the best conduct regarding the patients' feeding issues.

\section{REFERENCES}

1. United Nations, Departament of Economic and Social Affairs, Population Division [Internet]. World Population Ageing 2017- Highlight. [ Acesso em 2017 mar 27]. Disponível em: http://www.un.org/ en/development/desa/population/publications/pdf/ ageing/WPA2017_Highlights.pdf

2. Eglseer D, Halfens RJG, Schols JMGA, Lohrmann C. Dysphagia in hospitalized older patients: associated factors and nutritional interventions. J Nutr Health Aging. 2018;22(1):103-10. DOI:10.1007/ s12603-017-0928-x

3. Furuya H, Kikutani T, Igarashi K, Sagawa K, Yajima $\mathrm{Y}$, Machida $\mathrm{R}$ et al. Effect of dysphagia rehabilitation in patients receiving enteral nutrition at home nursing care: a retrospective cohort study. J Oral Rehabil. 2020;10.1111/joor.13030. DOI:10.1111/ joor. 13030

4. Zamora Mur A, Palacín Ariño C, Guardia Contreras Al, Zamora Catevilla A, Clemente Roldán E, Santaliestra Grau J. Importance of the detection of dysphagia in geriatric patients. Semergen. 2018;44(3):168-73. doi:10.1016/j. semerg.2017.03.001
5. Chatindiara I, Allen J, Popman A, Patel D, Richter $M$, Kruger $M$ et al. Dysphagia risk, low muscle strength and poor cognition predict malnutrition risk in older adults at hospital admission. BMC Geriatr. 2018;18(1):78. DOI:10.1186/s12877-018-0771-x

6. Gonçalves MLV, Broglio GAF, Lozano AC, Lamari NM. Perfil dos idosos usuários de via alternativa de alimentação reinternados em hospital público. RBCEH. 2015;12(1):20-7.

7. Nogueira SCJ, Carvalho APC, Melo CB, Morais EPG, Chiari BM, Gonçalves MIR. Profile of patients using alternative feeding route in a general hospital. Rev. CEFAC. 2013;15(1):94-104.

8. Conselho Federal de Fonoaudiologia. RESOLUÇÃO CFFa no 492, de 7 de abril de 2016. Dispõe sobre a regulamentação da atuação do profissional fonoaudiólogo em disfagia e dá outras providências. 7 apr 2016.

9. Conselho federal de fonoaudiologia. Parecer CFFa no 40, de 18 de fevereiro de 2016. Dispõe sobre a participação do Fonoaudiólogo na Equipe Multidisciplinar de Terapia Nutricional. 18 feb 2016.

10. Wei J, Chen W, Zhu M, Cao W, Wang X, Shi H. Guidelines for parenteral and enteral nutrition support in geriatric patients in China. Asia Pac J Clin Nutr. 2015;24(2):336-46.

11. Barroqueiro PC, Lopes MKD, Moraes AMS. Speech therapy criteria to indicate an alternative feeding route at an intensive care unit in a university hospital. Rev. CEFAC. 2017;19(2):190-7.

12. Carmo LFS, Santos FAA, Mendonça SCB, Araújo $B C L$. Management of the risk of bronchoaspiration in patients with oropharyngeal dysphagia. Rev. CEFAC. 2018;20(4):532-40.

13. Mundi MS, Patel J, McClave SA, Hurt RT. Current perspective for tube feeding in the elderly: from identifying malnutrition to providing of enteral nutrition. Clin Interv Aging. 2018;13:1353-64.

14. Wirth R, Dziewas R, Beck AM, Clavé P, Hamdy $S$, Heppner $\mathrm{HJ}$ et al. Oropharyngeal dysphagia in older persons- from pathophysiology to adequate intervention: a review and summary of an international expert meeting. Clin Interv Aging. 2016;11:189-208.

15. Rodrigues KA, Machado FR, Chiari BM, Rosseti HB, Lorenzon P, Gonçalves MIR. Swallowing rehabilitation of dysphagic tracheostomized patients under mechanical ventilation in intensive care units: a feasibility study. Rev Bras Ter Intensiva. 2015;27(1):64-71. 
16. Andrade JS, Oliveira de Jesus WW, Paranhos LR, Domeni DR, César CPHAR. Effects of speech therapy in hospitalized patients with post-stroke dysphagia: a systematic review of observational studies. Acta Med Port. 2017;30(12):870-81.

17. Luchesi KF, Campos BM, Mituuti CT. Identification of swallowing disorders: the perception of patients with neurodegenerative diseases. CoDAS. 2018;30(6):e20180027.

18. Carmo LFS, Santos FAA, Mendonça SCB, Araújo $\mathrm{BCL}$. Management of the risk of bronchoaspiration in patients with oropharyngeal dysphagia. Rev. CEFAC. 2018;20(4):532-40.

19. Andrade AG, Lima GM, Albuquerque JWA, Anijar NP, Teixeira RC. Processo de decanulação em pacientes acometidos por traumatismo cranioencefálico: estudo realizado em um hospital de trauma, na região metropolitana de Belém, PA. Rev Fac Ciênc Méd Sorocaba. 2017;19(4):196-200.

20. Lima DF, Pelzer MT, Barros EJL, Semedo DSR, Rosales A. Factors that make it difficult the oral feeding in elderly hospitalized. Revista enfermaria global. 2017;(48):453-64.

21. Davies N, Mathew R, Wilcock J, Manthorpe J, Sampson EL, Lamahewa $\mathrm{K}$ et al. A co-design process developing heuristics for practitioners providing end of life care for people with dementia. BMC Palliat Care. 2016;15(68):1-11.

22. Berkman C, Ahronheim JC, Vitale CA. SpeechLanguage pathologists' views about aspiration risk and comfort feeding in advanced dementia. Am J Hosp Palliat Care. 2019;36(11):993-8. DOI:10.1177/1049909119849003. 


\section{APPENDIX 1}

\section{Investigation questionnaire on the indication for and removal of an alternative feeding route in older adults}

\section{Identification data:}

Name:

Date: /2018

Sex: ( ) F ( ) M $\quad$ Age: ( ) 18-29 years ( ) 30-40 years ( ) 50-60 years

Position: ( ) medical preceptor ( ) medical resident

Professional training: ( ) specialization ( ) medical residency ( ) master’s degree ( ) doctor's degree

Time of experience: ( ) up to 5 years ( ) 5-10 years ( ) 10 to 20 years ( ) over 20 years

Department:

1. What are the main criteria taken into account to indicate an alternative feeding route in older adults?

\begin{tabular}{|l|l|l|}
\hline Criteria & \multicolumn{1}{|c|}{ Yes } & No \\
\hline Patient's age & & \\
\hline Underlying disease & & \\
\hline Progression of the disease & & \\
\hline Clinical condition & & \\
\hline Nutritional status & & \\
\hline Frailty & & \\
\hline Respiratory condition & & \\
\hline Consciousness level & & \\
\hline Dysphagia assessment by a speech therapist & & \\
\hline
\end{tabular}

2. When do you request the participation of a speech therapist to indicate and alternative feeding route?
( ) Always
( ) Frequently
( ) Occasionally
( ) Rarely
( ) Never

3. In cases when speech therapists do not participate in the indication of the alternative feeding route, but are is requested later to assess and probably follow-up on the older patient, what are the medical criteria used to request the speech therapist after having introduced the alternative feeding route?

\begin{tabular}{|l|l|l|}
\hline Criteria & Yes & No \\
\hline Complaints of dysphagia (coughing, choking, globus sensation) & & \\
\hline Risk of bronchoaspiration & & \\
\hline Inappetence & & \\
\hline Change in the nutritional status & & \\
\hline Assessment of alternative feeding route extubation & & \\
\hline
\end{tabular}


4. In cases of patients who are already being followed up by a speech therapist for dysphagia, what actions do you take from the medical standpoint?

( ) I always read the speech therapist's records and discuss the patient's progress

( ) I do not read the records and do not discuss with the professional

( ) I occasionally read the speech therapist's records and discuss the patient's progress

5. What are the medical criteria to remove the alternative feeding route in the hospital?

\begin{tabular}{|l|l|l|}
\hline Criteria & Yes & \\
\hline Stable clinical condition & & No \\
\hline Stable respiratory condition & & \\
\hline Adequate nutritional support & & \\
\hline Hospital discharge & & \\
\hline Comfort diet & & \\
\hline
\end{tabular}

6. In case it is decided for the removal, what medical procedures are taken?

( ) I do not request an assessment by a speech therapist

( ) I request an assessment by a speech therapist and wait for the professional's evaluation

7. How important is the speech therapist during the process of removal of the alternative feeding route in older adults?
( ) Extremely important
( ) Very important
( ) Moderately important
( ) Little important
( ) Not important 